\title{
Harmonisasi masyarakat plural: Praktik sosial di sekolah teologi untuk membangun nasionalisme Indonesia yang inklusif
}

\author{
Paulus S. Widjaja \\ Fakultas Teologi Universitas Kristen Duta Wacana, Yogyakarta \\ pauluswidjaja@staff.ukdw.ac.id
}

https://orcid.org/00000002-2953-2110

Keywords:

character;

Duta Wacana;

nationalism;

primordialism;

social practice;

karakter;

nasionalisme;

primordialisme;

praktik sosial

\section{Article History}

Submitted: August 19, 2021

Revised: September 09, 2021

Accepted: Sept. 18, 2021

DOI: https://doi.org/

10.30995/kur.v7i2.359

Copyright: (02021, Authors.

License:

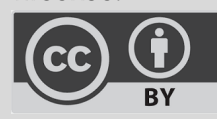

Scan this QR,

Read Online

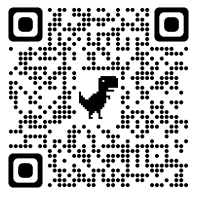

Abstract: Indonesian Nationalism is historic and ethical, not natural. It was born out of a shared history of various groups in Indonesia, in their struggle against the colonials, and of an ethical decision that those groups consciously took to become one nation. Such an inclusive nationalism must be intentionally developed structurally, systemically, and continuously by all the elements of the Indonesian nation, lest it would be wiped out by centralism, primordialism disguising in the form of dominant-religion-based nationalism, and unjust distribution of membership along with all its respected rights. Using the analysis from the perspective of Character Ethics, this article shows that theological schools have an important role in the character formation of inclusive nationalism through social practice in theological schools. Social practice is not simply a series of activities, but a series of intentional actions which are done together repeatedly by the whole members of the community. The history of an institution that was intended to prepare pastor assistants in Yogyakarta until it becomes the Faculty of Theology, Universitas Kristen Duta Wacana, at present is presented in this article as a model of effective social practice in the formation of inclusive nationalism. The research focuses on the intersubjective relations between all members of the Duta Wacana community, which reflects the very rich and deeply human experience, that takes place in the local everyday life, including various policies that are born out of that relationship with the religious-cultural identity that becomes its context.

Abstrak: Nasionalisme Indonesia bersifat historis dan etis, bukan alami. la lahir dari sejarah bersama kelompok-kelompok bangsa Indonesia melawan penjajah kolonial dan dari keputusan etis yang mereka ambil untuk menjadi satu bangsa Indonesia. Nasionalisme yang inklusif semacam itu harus dengan sengaja ditumbuhkembangkan secara terstruktur, sistemik, dan berkesinambungan oleh segenap elemen bangsa agar tidak tergerus oleh ancaman sentralisme, primordialisme yang tersamar dalam bentuk nasionalisme berbasis agama dominan, dan ketidakadilan distribusi keanggotaan beserta semua hak yang mengikutinya. Dengan menggunakan analisis dari perspektif Etika Karakter, tulisan ini menunjukkan bahwa sekolah-sekolah teologi memiliki peran penting untuk membentuk karakter nasionalisme yang inklusif melalui praktik sosial di sekolah-sekolah teologi terkait. Praktik sosial bukanlah sekadar rangkaian kegiatan, melainkan rangkaian tindakan yang dengan sengaja dilakukan secara bersama-sama berulang-kali oleh segenap anggota komunitas. Sejarah lembaga pendidikan asisten pendeta di Yogyakarta hingga menjadi Fakultas Teologi Universitas Kristen Duta Wacana diangkat dalam tulisan ini sebagai sebuah model praktik sosial yang terbukti efektif membentuk nasionalisme yang inklusif. Penelitian difokuskan pada relasi intersubjektif di antara segenap anggota komunitas ini, yang mencerminkan pengalaman insani yang sangat kaya dan mendalam, yang terjadi sehari-harinya dalam konteks lokalitas hidup, termasuk berbagai kebijaksanaan yang lahir dari relasionalitas tersebut serta identitas kultural religius yang menjadi konteksnya. 


\section{Pendahuluan}

Pada tanggal 6 Januari 2021 semua mata di dunia tertuju pada peristiwa mengerikan yang terjadi di Gedung Capitol, Amerika Serikat, tempat kerja para anggota dewan legislatif dari kedua kamar, Konggres dan Senat. Ratusan pengikut setia Donald Trump menyerbu ke dalam Gedung Capitol untuk menghentikan proses sertifikasi Joe Biden sebagai presiden baru Amerika Serikat menggantikan Donald Trump. Peristiwa kekerasan yang mengakibatkan lima orang meninggal dunia dan lebih dari 140 orang lainnya terluka itu menunjukkan loyalitas buta para demonstran terhadap Trump. ${ }^{1}$ Peristiwa itu juga ironis karena Amerika Serikat selama ini dipandang oleh masyarakat internasional sebagai pusat dan panutan demokrasi.

Demonstrasi yang penuh kekerasan itu sebenarnya sudah bisa diramalkan jauh hari sebelumnya. Pemimpin kharismatik seperti Donald Trump dengan ego yang demikian besar jelas tidak mudah menerima kekalahan dirinya begitu saja. Tetapi, lebih daripada itu, penyerangan Gedung Capitol itu sebenarnya sudah bisa diramalkan sejak Trump melontarkan jargonnya yang sangat populer, MAGA (Make America Great Again). Tersamar di balik kedok nasionalisme, jargon ini pada hakikatnya adalah sebuah Chauvinisme. Tak ada niatan sedikitpun juga di balik jargon tersebut akan persatuan nasional yang merengkuh semua orang tanpa memandang latar belakang apa pun. Apa yang dimaksudkan Trump sebagai "America" di balik jargon MAGA tak lain dan tak bukan adalah kelompok laki-laki kulit putih Amerika. Ini adalah Chauvinisme yang sangat hegemonik, bukan nasionalisme.

Nasionalisme adalah "sebuah konsep mengenai jati diri kebangsaan yang berfungsi dalam penetapan identitas individu di antara masyarakat dunia." ${ }^{2}$ Di Indonesia, semangat nasionalisme di masa lalu telah melahirkan gerakan Budi Utomo pada tanggal 20 Mei 1908, ikrar Sumpah Pemuda pada tanggal 28 Oktober 1928, dan bahkan Proklamasi Kemerdekaan Indonesia pada tanggal 17 Agustus 1945. Dalam nasionalisme ini, tidak ada semangat chauvinisme yang hegemonik. Masyarakat Jawa bersedia menerima Bahasa Melayu sebagai rujukan bagi bahasa nasional karena menyadari bahwa Bahasa Melayu sudah lebih dikenal secara luas oleh masyarakat Indonesia, dan tidak memaksakan Bahasa Jawa sebagai rujukan. Para pendiri bangsa Indonesia yang beragama Islam juga memiliki jiwa besar untuk tidak memaksakan Indonesia menjadi negara agama berlandaskan agama dominan pada saat kemerdekaan Republik Indonesia. Sema-ngat yang ditunjukkan adalah semangat nasionalisme sejati. Dalam nasionalisme ini hanya ada rasa kebersamaan sebagai satu bangsa Indonesia dengan semua warganya berdiri setara. Inilah nasionalisme yang inklusif; semua dirangkul, tak satupun disingkirkan atau direndahkan.

Frans Magniz-Suseno berpendapat bahwa gagasan akan nasionalisme Indonesia tidak bisa dilepaskan dari gagasan akan persatuan nasional. Magnis-Suseno menyitir pernyataan Sukarno yang terinspirasi oleh pemikiran Ernest Renan tentang hasrat untuk bersama dan pemikiran Otto Bauer tentang komunitas senasib, bahwa kesatuan bangsa Indonesia bukanlah kesatuan yang bersifat alami karena dorongan kesamaan yang dimiliki oleh kelompok-kelompok suku dan agama yang tinggal di Indonesia sebagaimana bisa dijumpai dalam nasionalisme Eropa. Kesatuan bangsa Indonesia adalah kesatuan historis dan etis. Disebut kesatuan historis karena kesatuannya berdasarkan pada sejarah sebagai komunitas senasib yang sama-sama berjuang melawan penjajahan. Disebut sebagai kesatuan etis karena kesatuannya merupakan keputusan etis dari kelompok-kelompok yang berbeda yang memang memiliki hasrat bersama untuk hidup sebagai satu bangsa. ${ }^{3}$

Di tempat lain, B. C. Upreti menegaskan perbedaan mendasar antara nasionalisme yang berkembang di Eropa dan nasionalisme yang berkembang di Asia. Menurut Upreti, nasionalisme

1 "2021 Storming of the United States Capitol," Wikipedia, May 23, 2021, accessed May 23, 2021, https://en.wikipedia.org/w/index.php?title=2021_storming_of_the_United_States_Capitol\&oldid=1024667406.

${ }^{2}$ Anggraeni Kusumawardani and Faturochman, "Nasionalisme," Buletin Psikologi XII, no. 2 (Desember 2004): 64.

${ }^{3}$ Frans Magnis-Suseno, "Persatuan Indonesia: Pancasila, Paham Kebangsaan Dan Integritas Nasional," in Pancasila Sebagai Ideologi Terbuka: Problema Dan Tantangannya, ed. Alex Lanur (Yogyakarta: Kanisius, 1995). 
Eropa berawal dari homogenitas. Bangsa-bangsa yang ada di Eropa menolak kekaisaran yang majemuk, dan masing-masing kelompok homogen kemudian membentuk negaranya, nationnya, sendiri-sendiri sesuai dengan pengelompokan suku bangsa yang ada. Nasionalisme Eropa dengan demikian mengakibatkan terjadinya perpecahan. Berbeda dari itu, nasionalisme yang berkembang di Asia justru berawal dari heterogenitas. Bangsa-bangsa di Asia mendirikan negaranya sendiri-sendiri bukan karena menolak kemajemukan yang ada, namun karena menolak pemerintah kolonial yang menjadi musuh bersama berdasarkan dorongan penentuan nasib sendiri. Oleh karena itu, setelah memerdekakan diri, negara-negara di Asia juga tetap memertahankan kemajemukan yang sudah lama ada. Tidak ada kemajemukan asali yang dihapuskan demi nasionalisme. Nasionalisme Asia dengan demikian menyatukan. ${ }^{4}$

Jika Suseno mengingatkan bahwa nasionalisme Indonesia didasarkan pada sejarah senasib melawan penjajahan dan keputusan etis dari kelompok-kelompok majemuk yang ada di Indonesia untuk bersatu, maka Upreti menegaskan bahwa nasionalisme Asia, termasuk Indonesia, memiliki keunikan justru karena tetap memertahankan kemajemukan asali, maka Emanuel Gerrit Singgih memberi catatan kritis pada nasionalisme. Menurutnya, meskipun nasionalisme merupakan gagasan yang luhur dan mulia, namun penekanan yang berlebihan pada nasionalisme juga bisa membawa dampak buruk, yaitu penghapusan kemajemukan itu sendiri. Nasionalisme Indonesia bisa dengan mudah terjerumus ke dalam etnisisme, entah dalam bentuk pengagungan etnisitas tertentu, atau pengagungan nasionalitas. Kedua bentuk tersebut, meskipun berbeda istilah dan cakupan, namun memiliki kesamaan spirit, yaitu eksklusifisme. ${ }^{5}$ Atas nama wawasan kebangsaan dan nasionalisme, kemajemukan ditiadakan demi kesatuan dan kesamaan. Upaya untuk menyikapi kemajemukan yang ada sambil memerkuat persatuan nasional, bisa saja menjadi ekstrim, di mana kemajemukan justru dilebur menjadi keseragaman atas nama wawasan kebangsaan dan nasionalisme. Etnisisme dianggap sebagai warisan kolonial yang perlu diganti dengan nasionalisme. Partikularitas tidak lagi diperhatikan karena semua dilebur dalam universalitas bernama "bangsa Indonesia." Keperbedaan dihapus demi kesamaan. Gereja-gereja pun kemudian tidak lagi bersikap kritis terhadap semangat nasionalisme yang didengungkan pemerintah. Dinamika ini ditunjukkan Singgih melalui analisisnya terhadap sikap Persekutuan Gerejagereja di Indonesia (PGI). PGI mencurigai etnisitas sebagai unsur negatif yang bisa menghalangi nasionalisme, dan oleh karenanya etnisitas kemudian dihisapkan ke dalam nasionalisme. Wawasan kebangsaan dianggap sebagai jawaban tepat atas bahaya pembentukan negara Islam, dan dengan demikian melindungi eksistensi umat Kristen. Namun ada kontradiksi yang terjadi di lapangan. Di aras nasional, orang-orang Kristen menggunakan wacana nasionalisme, tapi di aras regional, banyak orang Kristen yang mendukung diberlakukannya peraturan-peraturan daerah yang khas Kristen di wilayah-wilayah di mana umat Kristen dominan. ${ }^{6}$

Suseno dan Upreti dengan tepat menunjukkan bahwa nasionalisme yang berkembang di Indonesia adalah sebuah pilihan sadar dari segenap elemen bangsa Indonesia untuk bersatu di tengah kemajemukan. Sedangkan Singgih mengingatkan bahwa nasionalisme yang terlalu terobsesi oleh persatuan, bisa saja malah berubah menjadi nasionalisme yang eksklusif, yang meniadakan kemajemukan atas nama persatuan (baca, keseragaman). Itu artinya, segenap warga masyarakat dan bangsa Indonesia harus bisa menjaga keseimbangan antara semangat untuk bersatu di satu pihak dan semangat untuk menghargai kemajemukan di lain pihak. Namun para pakar di atas belum mengutarakan bagaimana konkritnya gagasan tentang nasionalisme yang inklusif itu bisa diwujudkan? Nasionalisme yang di satu pihak ingin menjaga persatuan bangsa, namun di pihak lain juga menghargai kemajemukan.

${ }^{4}$ B. C. Upreti, "Nationalism in South Asia: Trends and Interpretations," The Indian Journal of Political Science 67, no. 3 (2006): 535-544.

${ }^{5}$ Emmanuel Gerrit Singgih, Iman dan politik dalam era reformasi di Indonesia (Jakarta: BPK Gunung Mulia, 2000), 4.

${ }^{6}$ Emmanuel Gerrit Singgih, Mengantisipasi Masa Depan: Berteologi Dalam Konteks Di Awal Milenium III (Jakarta: BPK Gunung Mulia, 2004). 
Persatuan bangsa Indonesia memang bukan sesuatu yang taken for granted, yang bisa berjalan dan bertahan sendiri tanpa jerih juang segenap anggota komunitas bangsa Indonesia untuk menjaga dan memeliharanya. Persatuan bangsa Indonesia bisa diumpamakan seperti kesatuan antara suami-istri yang masing-masing memang memutuskan berdasarkan hati nuraninya sendiri untuk bersatu dengan yang lain. Oleh karena itu persatuan tersebut perlu dengan sengaja dijaga dan dipelihara. Namun pada saat yang sama, upaya menjaga dan memelihara persatuan tersebut juga tidak boleh menindas apalagi menghapus kemajemukan yang ada. Partikularitas dan keunikan masing-masing kelompok yang membentuk bangsa Indonesia tidak boleh dikorbankan demi sebuah persatuan sederhana. Oleh karena itu pertanyaan yang perlu diajukan adalah, hal-hal apa yang bisa mengancam pengembangan nasionalisme Indonesia yang inklusif, yang bahkan bisa membuat bangsa Indonesia mengkhianati kesatuannya sendiri? Dan bagaimana nasionalisme yang inklusif itu bisa dikembangkan oleh elemen-elemen bangsa Indonesia, termasuk sekolah-sekolah teologi, melalui upaya-upaya yang terstruktur, sistemik, dan berkesinambungan? Itulah pertanyaan-pertanyaan yang ingin dijawab dalam tulisan ini.

\section{Metode}

Pertanyaan-pertanyaan yang sudah disampaikan di atas akan dijawab dengan menggunakan analisis kritis dari perspektif teori Etika Karakter, khususnya terkait Praktik Sosial, atas pengalaman intersubjektif segenap anggota komunitas Sekolah Tinggi Teologi Duta Wacana, Yogyakarta yang di kemudian hari berkembang menjadi Fakultas Teologi Universitas Kristen Duta Wacana. Tujuan dari analisis ini adalah untuk menemukan apa yang bisa dilihat sebagai sebuah kearifan lokal, yaitu "filsafat yang hidup di dalam hati masyarakat, berupa kebijaksanaan hidup, way of life, dan sejenisnya." Istilah "lokal" di sini tidak terutama merujuk pada satu area geografis tertentu, tapi pada kehidupan manusia dalam sebuah relasi intersubjektif di antara orang-orang yang tinggal di satu wilayah tertentu, dalam hal ini Fakultas Teologi Universitas Kristen Duta Wacana. Relasi intersubjektif itu sendiri mencerminkan pengalaman insani yang sangat kaya dan mendalam, yang terjadi sehari-harinya dalam konteks lokalitas hidup, termasuk berbagai kebijaksanaan yang lahir dari relasionalitas tersebut serta identitas kultural religius yang menjadi konteksnya. $^{7}$

\section{hasil dan Pembahasan}

\section{Ancaman-ancaman terhadap Nasionalisme Indonesia}

Sebagaimana sudah dikatakan terdahulu, bahwa sudah dari sejak awal mulanya, bangsa Indonesia adalah bangsa yang majemuk. Kesatuan yang terbentuk secara normatif sejak dideklarasikannya Sumpah Pemuda pada tanggal 28 Oktober 1928 adalah kesatuan yang muncul dari hasrat untuk hidup bersama. Kesatuan sebagai bangsa Indonesia ini bahkan muncul jauh sebelum ada kesatuan sebagai negara Indonesia. Kelak ketika kesatuan ini membutuhkan batasan teritori secara legal formal, barulah lahir negara Indonesia. Dalam kaitan dengan nasionalisme ini, MagnisSuseno mengidentifikasi adanya tiga ancaman besar, yaitu Sentralisme, Primordialisme, dan Ketidak-adilan Sosial. ${ }^{8}$ Sentralisme bisa menjadi bahaya karena sentralisme merupakan sebuah bentuk represi pusat atas daerah, di mana daerah semata-mata dijadikan objek dari kebijakan pusat guna mengeruk keuntungan bagi pusat melalui eksploitasi kekayaan daerah. Sentralisme semacam inilah yang seringkali memicu terjadinya separatisme di Indonesia. Peraturan terkait otonomi daerah ataupun sistem pengelolaan desa yang sudah diberlakukan dalam kenyataannya juga membawa dampak tersendiri yang tidak begitu menguntungkan bagi daerah. ${ }^{9}$

${ }^{7}$ F. X. Eko Armada; Riyanto, Metodologi: Pemantik dan Anatomi Riset Filosofis Teologis (Malang: Widya Sasana Publication, 2020), 16-23, accessed September 18, 2021, //librarystftws.org/perpus/index.php?p=show_detail\&id=17302.

${ }^{8}$ Magnis-Suseno, "Persatuan Indonesia: Pancasila, Paham Kebangsaan Dan Integritas Nasional," 55-60.

${ }^{9}$ Ibid., 56-57. 
Sementara terkait primordialisme, perlu dipahami terlebih dahulu bahwa sejauh primordialisme tersebut bersifat primer, maka primordialisme semacam itu tidak dengan sendirinya bermasalah. Setiap manusia memang lahir dalam sebuah kelompok primordial. Primordialisme primer sekedar menegaskan kesadaran diri sebagai anggota dari sebuah kelompok tertentu, yang berbeda dari kelompok-kelompok lain. Namun ketika kesadaran tersebut berkembang menjadi perasaan superioritas, maka primordialisme primer sudah berkembang menjadi primordialisme sekunder. Primordialisme semacam inilah yang mengancam nasionalisme, karena perasaan superior dengan mudah menjadi kebencian yang mendorong seseorang atau sekelompok orang menyingkirkan kelompok-kelompok lain dalam komunitas yang dipandang sebagai ancaman atas superioritasnya. ${ }^{10}$

Primordialisme sekunder juga bisa tersamar dalam bentuk nasionalisme berbasis agama dominan. Dalam penelitian yang saya dan teman-teman dosen Fakultas Teologi, Universitas Kristen Duta Wacana, lakukan untuk melihat dampak politik identitas yang negatif pada perilaku orang-orang Kristen di ruang publik di Daerah Istimewa Yogyakarta, kami menemukan bahwa politik identitas yang negatif memengaruhi perilaku responden di ruang publik hingga $25.8 \% .{ }^{11}$ Prosentase ini memang tidak bisa dikatakan besar, tapi juga tidak bisa dikatakan kecil. Yang jelas terlihat adalah bahwa perilaku orang-orang Kristen di wilayah yang terkenal sebagai Kota Toleransi, ternyata cukup banyak dipengaruhi oleh politik identitas yang negatif. Demikian pula ketika penelitian kami perluas mencakup umat beragama di Daerah Istimewa Yogyakarta dari enam agama yang diakui pemerintah, fakta serupa juga terkonfirmasi, meskipun terselubung. Umat lintas agama dengan tegas mendukung perilaku-perilaku di ruang publik yang dilandaskan pada religiusitas perdamaian. Namun mereka ragu-ragu untuk mengecam perilaku-perilaku di ruang publik yang dilandaskan pada politik identitas yang negatif. Keragu-raguan semacam ini menunjukkan bahwa jauh di lubuk hati umat lintas agama ini, sebenarnya mereka juga secara diam-diam mengonfirmasi operasionalisasi politik identitas yang negatif. ${ }^{12}$

Politik identitas merupakan fenomena yang perlu diwaspadai. Meskipun tidak selalu membawa dampak negatif, politik identitas biasanya mendorong kelompok-kelompok agama di masyarakat berjuang guna mendapatkan kuasa politik; satu hal yang berbahaya bagi kelanggengan hidup bersama. Orang-orang bisa dengan mudah bersikap acuh tak acuh dan tidak peduli pada orang-orang yang berbeda secara sosial-kultural, atau mereka menjadi eksklusif dalam mendefinisikan identitas sosial-kultural mereka. ${ }^{13}$ Lebih berbahaya lagi jika kelompok-kelompok agama tidak lagi berkiprah hanya terkait dengan persoalan-persoalan supranatural yang menjadi inti agama, tapi juga berjuang dan berkompetisi guna mendapatkan kuasa politik. Dalam situasi semacam itu maka militansi agama bisa dengan mudah bertransformasi menjadi ekstremisme agama, yang tidak jarang penuh dengan kekerasan. Keadaannya bertambah buruk ketika negara memraktikkan politik pilih kasih atas satu kelompok agama, sementara tidak begitu memedulikan kelompok-kelompok agama yang lain. Kelompok agama dominan pada gilirannya akan menggunakan pengaruh politik mereka untuk mendapatkan keuntungan bagi kelompok agamanya, sambil menyingkirkan kelompok-kelompok agama lain ke pinggiran. ${ }^{14}$ Kesadaran kolektif dari kelompok agama dominan kemudian menjadi begitu kaku karena identitas kolektif religius berkelindan dengan afiliasi politik, dan kebenaran religius merambah ke dalam politik. Kewar-

${ }^{10}$ Ibid., 57-59.

${ }^{11}$ Paulus S. Widjaja et al., Dampak Politik Identitas Terhadap Perilaku Umat Kristiani Di Ruang Publik Di Daerah Istimewa Yogyakarta (Yogyakarta: Taman Pustaka Kristen, 2020), accessed May 17, 2020, http://library.ukdw.ac.id/main/opac/index.php?p=show_detail\&id=46326.

${ }^{12}$ Paulus Sugeng Widjaja, Djoko Prasetyo Adi Wibowo, and Imanuel Geovasky, "Politik Identitas Dan Religiusitas Perdamaian Berbasis Pancasila Di Ruang Publik," GEMA TEOLOGIKA: Jurnal Teologi Kontekstual dan Filsafat Keilahian 6, no. 1 (April 30, 2021): 95-126.

${ }^{13}$ Peter Jonkers, "How to Break the III-Fated Bond between Religious Truth and Violence," in Religious Truth and Identity in an Age of Plurality, ed. Peter Jonkers and Oliver J. Wiertz (London and New York: Routledge, 2019), 246.

${ }^{14}$ Laurence R lannaccone and Eli Berman, "Religious Extremism: The Good, The Bad, and The Deadly," Public Choice 128 (July 28, 2006): 109-129. 
ganegaraan dan afiliasi dengan kelompok agama dominan menjadi dua sisi dari satu mata uang yang sama. ${ }^{15}$ Orang Filipina berarti Katholik, orang Indonesia berarti Muslim, orang Thai berarti Buddha, orang India berarti Hindu, dan seterusnya. Dalam situasi ini, ekstremisme agama dan kekerasan agama tersamar di balik tirai nasionalisme.

Ketika kelompok agama dominan merasa memiliki cukup kuasa politik di tangannya dan cenderung memertahankan status quo, maka nasionalisme berbasis agama dominan dipandang sebagai cara yang efektif untuk memertahankan identitas kelompok agama dominan tersebut. Penindasan terhadap kelompok-kelompok agama lainnya pun segera berubah menjadi penindasan oleh negara, dan berlangsung tersamar di bawah aturan-aturan legal terkait agama, seperti hukum penodaan atau penistaan agama, misalnya. Keterpecahan sosial dan kekerasan atas nama agama pun mengikuti. ${ }^{16}$

Di Indonesia, contohnya, sejak tahun 1999 sudah ada sekitar 110 peraturan terkait agama yang ditetapkan oleh badan legislatif maupun eksekutif, baik di tingkat nasional maupun di tingkat provinsi. Dari aturan-aturan ini, 51 peraturan (46\%) terkait dengan penodaan agama, dan 31 peraturan $(60 \%)$ dari 51 peraturan tersebut berkaitan dengan kelompok dan ajaran yang dianggap sesat. ${ }^{17}$ Di tahun 2007, Majelis Ulama Indonesia juga menetapkan kriteria bagi kelompok yang disebut sekte sesat. Sebagai akibatnya, kelompok-kelompok minoritas dalam Islam seperti Syiah dan Ahmadiyah, menjadi rentan di depan hukum dan masyarakat. Mereka sering dihukum oleh kelompok-kelompok masyarakat yang tidak menyukai mereka maupun oleh politisi. Situasi ini menjadi lebih buruk ketika delik penodaan agama dipandang sebagai delik pidana yang dihubungkan dengan Pasal 156A Kitab Undang-undang Hukum Pidana dan dengan UU PNPS No.1 Tahun 1965 tentang Pencegahan Penyalahgunaan dan/atau Penodaan Agama.

Keberadaan peraturan-peraturan terkait penodaan agama tidak hanya menguntungkan kelompok dominan di dalam agama Islam saja. Kelompok dominan dalam agama Kristen juga merasa diuntungkan dengan memanfaatkan peraturan-peraturan itu untuk menyingkirkan kelompok-kelompok yang dianggap sesat seperti Saksi Yehovah, Mormon, dan berbagai kelompok minoritas Kristen lainnya. Hal ini menunjukkan bahwa persoalannya tidak terletak pada agama per se, tetapi lebih pada kuasa politik yang dinikmati oleh kelompok agama dominan. Primordialisme agama telah berubah menjadi nasionalisme berbasis agama dominan, yang disertai kekerasan atas nama agama, dengan menargetkan kelompok-kelompok agama minoritas. Aturanaturan terkait agama semacam itu bahkan tidak memerhatikan bahwa terma-terma agama bisa bermakna berbeda di antara kelompok-kelompok agama yang menggunakan terma yang sama. Apa yang dimaksud sebagai "ibadah" atau "persekutuan," misalnya, bisa berbeda-beda pemaknaan dan praktiknya di antara kelompok-kelompok agama yang berbeda. Demikian pula dengan apa yang dimaksud dengan doa, pujian, meditasi, pendarasan, dan sebagainya.

Persoalan penodaan agama ini juga mengambil bentuk serta dinamika yang unik dan lebih rumit di era masyarakat digital, karena digerakkan oleh logika informasi digital yang lebih mengutamakan aksesibilitas, efisiensi pesan, dan unjuk kerja. Semuanya ini kemudian terserap ke dalam wacana politik dalam berbagai bentuk yang digunakan sebagai alat bagi pertarungan politik. Akibatnya, wacana ini melumpuhkan proses demokrasi itu sendiri karena masyarakat akhirnya

\footnotetext{
${ }^{15}$ Ahmad Muttaqin, "Meneguhkan Harmoni Muslim-Kristen: Mengayuh Di Antara Problem Dan Potensi," in Islam, Agama-Agama, Dan Nilai Kemanusiaan: Festschrift Untuk M. Amin Abdullah, ed. Moch Nur Ichwan and Ahmad Muttaqin (Yogyakarta: CISForm UIN Sunan Kalijaga, 2013), 140, 142-43; IRIN, "How to Reverse Buddhism's Radical Turn in Southeast Asia?," Refworld, last modified July 16, 2013, accessed December 30, 2020, https://www.refworld.org/docid/51e9102b4.html.

${ }^{16}$ Nilay Saiya, "Pluralism and Peace in South Asia," The Review of Faith \& International Affairs 17, no. 4 (2019): 12-13.

${ }^{17}$ Moch Nur Ichwan, "Manusiawi, Adil, Dan Beradab: Menuju Tadbir Humanistik Atas Keragaman Agama," in Islam, Agama-Agama, Dan Nilai Kemanusiaan: Festschrift Untuk M. Amin Abdullah, ed. Moch Nur Ichwan and Ahmad Muttaqin (Yogyakarta: CISForm UIN Sunan Kalijaga, 2013), 237-40; Zainal Abidin Bagir, "The Politics and Law of Religious Governance," in Routledge Handbook of Contemporary Indonesia, ed. Robert W. Hefner (Abingdon: Routledge, 2018), 284-295, accessed July 2, 2020, https://www.routledge.com/Routledge-Handbook-ofContemporary-Indonesia/Hefner/p/book/9781138644427.
} 
terdorong untuk lebih mementingkan persoalan batas-batas yang dapat diterima dalam wacana agama, daripada mendiskusikan soal-soal terkait peningkatan kehidupan beragama dan kesalehan personal. ${ }^{18}$

Sedangkan masalah ketidak-adilan memang merupakan masalah yang tidak langsung terlihat korelasinya dengan nasionalisme, namun masalah ini sebenarnya merupakan masalah paling serius yang mengancam nasionalisme dan membawa dampak jangka panjang. Nasionalisme yang sejati harus dibangun di atas dasar keadilan di mana kehidupan bersama yang adil dan manusiawi bisa dirasakan oleh semua anggota masyarakat. Untuk itu, segala macam diskriminasi, entahkah berdasarkan kesukuan, agama, atau golongan seseorang harus benar-benar dihapus, dan penghargaan serta penghormatan pada otonomi dan identitas budaya semua kelompok masyarakat dengan sengaja dibangun. ${ }^{19}$

Erat kaitannya dengan masalah ketidak-adilan, adalah ketidak-adilan yang muncul dari persoalan terkait keanggotaan (membership). Sebagaimana sudah disampaikan terdahulu, bahwa salah satu tolak ukur utama nasionalisme adalah keanggotaan pada satu kelompok bangsa. Namun persoalan keanggotaan ini juga bisa menjadi hambatan tersendiri bagi terbentuknya nasionalisme yang inklusif. Apa yang sudah disampaikan oleh Michael Walzer terkait keanggotaan dalam satu komunitas politik patut dicermati. ${ }^{20}$ "Human society," Walzer mengawali, "is a distributive community" di mana apa yang dimiliki seseorang senantiasa berasal dari anggota yang lain. ${ }^{21}$ Dan salah satu kebutuhan mendasar "is community itself: culture, religion, and politics. It is only under the aegis of these three that all the other things we need become socially recognized needs, take on historical and determinate form." 22 Dalam komunitas distributif semacam itu, keanggotaan dalam satu komunitas politik merupakan barang sosial utama yang didistribusikan oleh para anggota satu kepada yang lain dengan cara menerima seseorang ke dalam komunitas terkait. Keanggotaan pada gilirannya menentukan pilihan-pilihan distributif, yaitu dengan siapa, dari siapa, dan kepada siapa barang sosial terkait pilihan-pilihan tersebut diciptakan, dipelihara, dan didistribusikan. United Nations Development Programme (UNDP) menyatakan bahwa salah satu wujud keamanan insani (human security) adalah community security, yang menunjuk pada keamanan keanggotaan di tengah kelompok-kelompok masyarakat yang ada. ${ }^{23}$

Hak-hak azasi individu, yaitu hak untuk berserikat (berkomunitas), hak untuk hidup, dan hak untuk kemerdekaan merupakan hak-hak yang berkait-kelindan dengan keanggotaan seseorang dalam sebuah komunitas politik. ${ }^{24}$ Keanggotaan merupakan akibat langsung dari pewujudan hak untuk berserikat melalui mana sebuah komunitas politik terbentuk dan terpelihara dalam sebuah proses penentuan nasib sendiri, termasuk penetapan batas-batas teritorial serta kebijakan penerimaan dan penyingkiran yang berlaku di dalam komunitas itu. Tanpa hak ini maka tidak akan pernah ada "communities of character." ${ }^{25}$ Bukan saja dalam bentuk positif, keanggotaan juga merupakan wujud negatif dari hak untuk berserikat, karena merupakan hak yang dimiliki seorang individu untuk tidak disingkirkan dari komunitasnya. ${ }^{26}$ Keanggotaan juga terkait erat dengan hak untuk hidup di atas dasar mana bukan saja kehidupan, tapi kehidupan yang baik,

${ }^{18}$ Leonard Chrysostomos Epafras, Hendrikus Paulus Kaunang, and Syamsul Asri, "Religious Blasphemy and Monitory Society in Indonesian Digital Age," Jurnal Kawistara 9, no. 2 (October 19, 2019): 220.

${ }^{19}$ Magnis-Suseno, "Persatuan Indonesia: Pancasila, Paham Kebangsaan Dan Integritas Nasional," 59-60.

${ }^{20}$ Michael Walzer, Spheres Of Justice: A Defense Of Pluralism And Equality (New York: Basic Books, 1984), $31-63$.

${ }^{21}$ Ibid., 3.

22 Ibid., 65.

${ }^{23}$ Eko Prasetyono, Riefki Muna, and Mahmud Syaltout, Kaji Ulang Indeks Keamanan Manusia Indonesia 2013 (Jakarta: Kementrian PPN/Bappenas and United Nations Development Programme, 2013), 8, accessed September 16, 2021,

http://ditpolkom.bappenas.go.id/basedir/Kajian\%20Ditpolkom/3)\%20Kajian\%20Tahun\%202014/Indeks\%20Keaman an/Indeks\%20Keamanan.pdf.

${ }^{24}$ Glen Stassen, "Michael Walzer's Situated Justice," The Journal of Religious Ethics 22, no. 2 (1994): 375-399.

${ }^{25}$ Walzer, Spheres Of Justice, 62.

${ }^{26}$ Stassen, "Michael Walzer's Situated Justice," 384. 
diupayakan melalui "the communal provision of security and welfare." Pemeliharaan komunitas dalam bentuk keamanan dan kesejahteraan ini merupakan hal pertama yang para anggota dalam sebuah komunitas saling berhutang satu kepada yang lain, ${ }^{27}$ dan merupakan pewujudan keterikatan moral yang para anggota komunitas tersebut janjikan satu kepada yang lain dalam sebuah kontrak sosial. ${ }^{28}$ Akhirnya, keanggotaan mengandaikan hak untuk kemerdekaan melalui mana ada jaminan atas partisipasi seluruh anggota komunitas dalam pembuatan keputusan politik berdasarkan proses demokratis yang mengakui kesetaraan semua anggota. ${ }^{29}$ Konsekuensinya, hanya ada satu kewarga-negaraan dengan semua hak terkait yang didistribusikan kepada semua orang yang layak dalam sebuah komunitas politik bersama. Tidak boleh ada dominasi tirani dalam pendistribusian keanggotaan ini ataupun pertukaran keanggotaan dengan barang sosial yang lain.

Tetapi, keanggotaan sebagai sebuah barang sosial bisa disalah-gunakan sebagai alat dominasi, khususnya atas kelompok-kelompok yang lemah dan rentan. Kasus orang-orang keturunan Tionghoa di Indonesia bisa menjadi contoh. Menurut Ignas Kleden, ${ }^{30}$ konflik etnis di Indonesia memiliki sejarah panjang yang berakar dalam apa yang oleh para pakar ilmu sosial disebut sebagai pembagian kerja yang terstratifikasi secara etnis dalam perdagangan. Dalam skema ini, pemerintah kolonial Belanda membagi kelas pekerja ke dalam tiga kategori: para pedagang Eropa yang berurusan dengan perdagangan internasional, para pedagang Timur Jauh (Tionghoa, Arab, dan India) yang berurusan dengan perdagangan antarpulau, dan para pedagang inlander yang berurusan dengan perdagangan dalam skala mikro. Jika skema ini ditempatkan dalam bingkai teori Walzer di atas, maka jelaslah bahwa pembagian yang dibuat pemerintah kolonial Belanda ini bukan sekedar pembagian kerja, tapi sebenarnya merupakan pembagian keanggotaan. Pembagian ini telah melanggar hak untuk berserikat karena keanggotaan tidak lagi merupakan barang sosial yang dibagikan para anggota sebuah komunitas politik satu kepada yang lain semata-mata berdasarkan legalitas keanggotaan individu terkait, namun berdasarkan etnisitas dan pembagian kerja dalam perdagangan yang seharusnya tidak ada relevansinya sama sekali dengan keanggotaan dalam sebuah komunitas politik. Pemerintah kolonial Belanda juga memberikan gelargelar kehormatan seperti "Letnan," "Kapitan," dan "Mayor" kepada para pedagang keturunan Tionghoa berdasarkan kekayaan mereka, bukan berdasarkan keanggotaan mereka. Dengan demikian kekayaan yang seharusnya hanya mempunyai daya tukar di ranah ekonomi telah merambah ke luar ke ranah sosial-politik. Inilah dominasi. Hak untuk hidup serta hak untuk kemerdekaan (berpartisipasi) juga telah didistribusikan secara tidak adil dalam skema tersebut.

Dengan menciptakan skema semacam itu maka pemerintah kolonial Belanda bisa memertahankan dominasi mereka di Indonesia karena kelompok-kelompok yang ada di masyarakat sangat bergantung pada kemurahan hati penguasa guna mendapatkan hak-hak asasinya. Perbedaan etnis dan kekayaan dimanfaatkan untuk membangun diferensiasi ekonomi-politik guna melayani kepentingan pemerintah kolonial yang berkuasa, tanpa persetujuan dari para subjek yang terdampak oleh kebijakan tersebut. Keanggotaan dibedakan menjadi beberapa jenis dan didistribusikan kepada para anggota sebuah komunitas politik yang berbagi teritori yang sama. Hak-hak dasar yang menyatu dengan keanggotaan juga didistribusikan secara tidak adil berdasarkan kriteria yang ditentukan secara sepihak oleh penguasa. Keamanan yang seharusnya didistribusikan sebagai bentuk pemeliharaan komunitas pada semua anggota berdasarkan keanggotaan mereka, misalnya, terpaksa harus dibeli; dan kekayaan dengan demikian digunakan untuk membeli barang sosial yang seharusnya tidak dapat dan tidak boleh didapatkan dengan kekayaan.

Sayangnya, skema ini terus dipelihara hingga masa pasca kemerdekaan. Warga keturunan Tionghoa dikungkung dalam ranah ekonomi, tanpa akses politik memadai; sementara warga in-

\footnotetext{
${ }^{27}$ Walzer, Spheres Of Justice, 64-65, 68; bdk. 31-35.

${ }^{28}$ Ibid., 82-83, bdk. 93.

${ }^{29}$ lbid., 112-115, bdk. 60.

${ }^{30}$ Ignas Kleden, "Stratifikasi Etnis Dan Diskriminasi," in Pri Dan Nonpri Mencari Format Baru Pembauran, ed. Moch. Sa'dun M (Jakarta: Pustaka Cidesindo, 1999).
} 
lander dikotakkan dalam ranah politik, tanpa akses ekonomi memadai. Hanya mereka yang menjadi kroni penguasa yang memiliki akses, baik untuk ranah ekonomi maupun untuk ranah politik. Akibatnya, mereka yang memiliki akses politik terdorong untuk menukarkan akses tersebut dengan manfaat ekonomi, dan sebaliknya, mereka yang memiliki akses ekonomi menukarkannya dengan manfaat politik. Satu barang sosial digunakan untuk mendapatkan barang sosial lain yang berada di luar ranahnya; kekayaan ditukar dengan kuasa politik, dan kuasa politik dipakai untuk mendapatkan kekayaan. Ranah keanggotaan, ranah kuasa politik, dan ranah kekayaan bertumpang-tindih hingga tidak ada lagi batas yang jelas di antara ranah-ranah tersebut. Penguasa negara menjadi satu-satunya agen distribusi untuk semua barang sosial. Penyalahgunaan keanggotaan sebagai alat dominasi semacam ini sudah merusak nasionalisme itu sendiri karena kesatuan nasional yang terbentuk adalah kesatuan semu di mana ada kelompok-kelompok dalam masyarakat yang dipaksa untuk berhutang budi pada kelompok lain dan penguasa demi untuk menjaga keanggotaannya dalam komunitas bangsa Indonesia.

\section{Proses Belajar Mengajar sebagai Praktik Sosial Menumbuh- Kembangkan Nasionalisme yang Inklusif}

Berhadapan dengan ancaman-ancaman nyata terhadap nasionalisme Indonesia sebagaimana dipaparkan di atas, bagaimana seharusnya lembaga-lembaga pendidikan, termasuk sekolahsekolah teologi, menyikapinya? Martin Luther King, Jr. telah dengan tepat sekali menunjukkan apa yang seharusnya menjadi tujuan dari pendidikan,

The function of education, therefore, is to teach one to think intensively and to think critically. But education which stops with efficiency may prove the greatest menace to society. The most dangerous criminal may be the man gifted with reason, but with no morals . . . We must remember that intelligence is not enough. Intelligence plus character-that is the goal of true education. The complete education gives one not only power of concentration, but worthy objectives upon which to concentrate. ${ }^{31}$

Apa yang ditekankan oleh Martin Luther King, Jr. adalah bahwa proses pendidikan tidak boleh hanya mengarus-utamakan persoalan efisiensi saja, apalagi di dalam era digital-mekanistik sekarang ini, namun juga, dan bahkan terutama, persoalan pembentukan karakter. Terkait dengan hal ini, Praktik Sosial menjadi penting sekali. Pembentukan karakter memang harus memerhatikan secara simultan empat pilar utama, yaitu Kebajikan, Tujuan/Pusat Hidup, Narasi, dan Praktik Sosial. ${ }^{32}$ Nara didik tidak akan pernah terbentuk karakternya sebagai seorang nasionalis yang inklusif hanya dengan duduk manis mengikuti perkuliahan Pendidikan Dasar Kewarganegaraan atau Pendidikan Moral Pancasila atau mata kuliah-mata kuliah lain terkait nasionalisme. Para nara didik harus terlibat dalam sebuah praktik sosial yang dengan sengaja ditumbuhkembangkan dan diberlakukan secara terstruktur, sistemik, dan berkesinambungan. Praktik sosial semacam itu akan membantu para nara didik bukan saja untuk mengenali kebajikan-kebajikan yang dibutuhkan bagi nasionalisme yang inklusif seperti empati, vulnerabilitas, kerendahan-hati, kesabaran, pengharapan, toleransi, harmoni dan sebagainya, namun juga bagaimana mewujudkan kebajikan-kebajikan itu sebagai jalan hidup. Hal ini penting sekali karena kebajikankebajikan yang membentuk karakter seseorang hanya bisa disemai melalui praktik sosial, learning by doing, "to practice virtue . . . by practicing virtue. ${ }^{\prime 33}$ Prosesnya mirip seperti seorang yang belajar berenang; bukan dengan mendengarkan instruksi saja, tapi dengan menceburkan dirinya ke dalam kolam renang dan benar-benar mempraktikkan gerakan renang yang diajarkan.

Praktik sosial harus dibedakan dari sekedar kegiatan insidental seperti kunjungan ke pantipanti sosial sebagai bagian dari aksi Paskah atau Natal, atau bagi-bagi sembako ketika terjadi

\footnotetext{
${ }^{31}$ Martin Luther King Jr., "The Purpose of Education," The Maroon Tiger, February 1947, accessed May 12, 2021, https://kinginstitute.stanford.edu/king-papers/documents/purpose-education.

32 Paulus S. Widjaja, "Ketupat Nasi: Melampaui Perbuatan, Membentuk Karakter," in Tetap Setia Dan Menjadi Berkat, ed. Paulus S. Widjaja (Yogyakarta: Komojoyo Press, 2021), 119-133.

${ }^{33}$ Johannes A. van der Ven, Formation of the Moral Self, 1st edition. (Grand Rapids, Mich: Eerdmans Pub Co, 1998), 383-84.
} 
bencana alam, atau bahkan acara-acara dialog lintas agama. Praktik sosial adalah praktik yang dilakukan bersama-sama berulang-kali oleh segenap anggota komunitas secara terstruktur, sistemik, dan berkesinambungan. Kata kunci di sini bukanlah terutama persoalan seberapa banyak seseorang mempraktikkan suatu tindakan, tapi seberapa intensifnya ia mempraktikkannya bersama-sama dengan yang lain. Seseorang bisa saja setiap hari berlatih menendang bola, misalnya, namun hal itu tidak dengan sendirinya membuat ia menjadi seorang pemain sepak bola yang handal. Latihan menendang bola yang ia lakukan setiap hari hanya akan membuatnya menjadi seorang yang memiliki ketrampilan menendang bola dengan baik, tapi tidak otomatis membuatnya menjadi seorang pemain sepak bola yang handal. Untuk bisa menjadi pemain sepak bola yang handal, orang tersebut harus terlibat secara terstruktur, sistemik, dan berkesinambungan dalam pertandingan-pertandingan sepak bola. Melalui keterlibatannya dalam pertandingan-pertandingan sepak bola itulah ia belajar berbagai macam tantangan dan cara mengatasi tantangan dalam permainan sepak bola. Demikian pula ia belajar untuk saling menguatkan dan mengasah keterampilan bersama sesama pemain bola yang lain. Pemain sepak bola dunia seperti Lionel Messi, contohnya, sudah terlibat dalam 920 pertandingan perebutan kejuaraan sepanjang karirnya, belum termasuk pertandingan-pertandingan persahabatan. Pun demikian dengan Cristiano Ronaldo yang sudah terlibat dalam 1066 pertandingan. ${ }^{34}$

Begitu pula halnya dengan masalah pembentukan karakter untuk menjadi seorang nasionalis yang inklusif. Hal ini tidak akan pernah bisa terjadi jika tidak ada praktik sosial yang dijalani dan dialami oleh para nara didik terkait dengan nasionalisme yang inklusif tersebut, termasuk dalam keseluruhan proses belajar mengajar di sekolah-sekolah teologi. Praktik sosial ini harus diintegrasikan baik dalam kurikulum eksplisit melalui mata kuliah-mata kuliah yang diajarkan, dalam kurikulum implisit melalui berbagai macam pelatihan dan pembinaan mahasiswa di kampus maupun asrama, dan juga dalam kurikulum ekstra-kurikuler seperti kegiatan-kegiatan olah raga atau seni. Sekolah-sekolah teologi bahkan juga harus mengritisi kurikulum null ketika sekolah-sekolah teologi tidak menyediakan praktik sosial yang membuat nara didik sadar akan perannya dalam menjaga dan memelihara nasionalisme Indonesia yang inklusif dan berlatih untuk mewujudkannya. Perlu diingat bahwa sekolah senantiasa merupakan ajang dan sarana yang sangat efektif untuk mendidik individu-individu guna menjadi warga negara yang baik. Ini merupakan tugas dari semua pemangku kepentingan, termasuk di dalamnya para dosen, nara didik, pengurus Yayasan, maupun gereja-gereja pendukung. H Richard Milner IV dengan tepat mengatakan,

Systemic, institutional shifts are important to build the kind of citizenry that allows us to take forward steps toward equity. To build organizational and institutional shifts, education leaders must remember that systems depend on individuals (such as policymakers, school leaders, educators, parents, and students) working in concert. Teachers must feel supported to teach in ways that honor all students and that disrupt, challenge, and call out the perpetuation of racist, sexist, homophobic, and xenophobic mindsets and discourses. Administrators have to build a culture of love, anti-hate, and liberation, and not expect teachers to engage in this work inside of their classroom without overt commitment and support from those in positions to make decisions. Depending on teachers alone to create changes is shortsighted and will not result in the real systemic, institutional, and enduring changes needed for sustainability. ${ }^{35}$

Setiap individu di dunia senantiasa membutuhkan komunitas untuk membentuk dirinya menjadi orang yang baik. Tidak seorangpun bisa melakukannya sendiri. Bahkan meskipun seseorang mempunyai niat baik sekalipun juga, niat baik itu tidak serta merta akan menuntunnya untuk melakukan tindakan-tindakan yang baik. Rasul Paulus pernah mengatakan, "Karena bukan apa yang aku kehendaki yang aku perbuat, tetapi apa yang aku benci, itulah yang aku perbuat"

\footnotetext{
34 "Messi vs Ronaldo - All Time Career Goals and Stats," MessivsRonaldo.App, accessed May 19, 2021, https://www.messivsronaldo.app/.

${ }^{35}$ H. Richard Milner IV, "Reimagining the Null Curriculum," Educational Leadership, November 2017, accessed May 19, 2021, http://www.ascd.org/publications/educational-leadership/nov17/vol75/num03/Reimaginingthe-Null-Curriculum.aspx.
} 
(Rom. 7:15). "It takes a village," kata Hillary Clinton. ${ }^{36}$ Meskipun seseorang memiliki maksud baik, namun maksud baik itu harus dengan sengaja dilatih dan dikembangkan dengan penuh disiplin melalui kebiasaan-kebiasaan yang terintegrasi dalam praktik sosial. Jiwa manusia harus dikondisikan "by habits to the right kind of likes and dislikes, just as land must be cultivated before it is able to foster seed, ${ }^{\prime 37}$ seperti seorang atlit yang dengan sengaja melatih dirinya mengembangkan ketrampilan-ketrampilannya. ${ }^{38}$ Apalagi, dalam teologi Kristen semua orang diyakini sebagai orang berdosa (Rom. 3:23) yang telah memberontak terhadap Allah. Tanpa latihan yang disengaja dalam praktik sosial, mustahil para nara didik di sekolah-sekolah teologi bisa menjadi orang-orang nasionalis yang inklusif. Rasul Paulus berujar tentang dirinya sendiri, "Sebab itu aku tidak berlari tanpa tujuan dan aku bukan petinju yang sembarangan saja memukul. Tetapi aku melatih tubuhku dan menguasainya seluruhnya, supaya sesudah memberitakan Injil kepada orang lain, jangan aku sendiri ditolak" (1Kor. 9:26-27).

Terkait dengan praktik sosial, perlu juga diingat bahwa konsep kebangsaan sebagaimana diandaikan dalam nasionalisme, perlu dibedakan dari konsep kenegaraan. Jauh sebelum negara Indonesia terbentuk, konsep kebangsaan sudah terlebih dahulu terbentuk pada masa pergerakan Budi Utomo. Namun sayangnya, dalam perkembangan selanjutnya, terutama setelah kemerdekaan Indonesia, konsep kebangsaan justru dihisap ke dalam konsep kenegaraan, sehingga identitas nasional begitu ditekankan dengan mengorbankan identitas kelompok. Ketika itu terjadi, maka konsep kebangsaan menjadi sesuatu yang sangat abstrak. Konsep kebangsaan adalah sesuatu yang hanya bisa dihayati dan diamalkan di tingkat lokal, bukan di tingkat nasional, karena di tingkat lokal itulah segala sesuatu menjadi sangat konkrit, tidak abstrak. ${ }^{39}$

Dalam terang inilah menarik untuk mencermati sejarah dan pergumulan Fakultas Teologi Universitas Kristen Duta Wacana (UKDW), Yogyakarta sebagai sebuah model praktik sosial yang terbukti efektif membentuk nasionalisme yang inklusif. Fakultas Teologi UKDW lahir pada tahun 1906 sebagai sebuah lembaga pendidikan yang bertujuan melengkapi dan memersiapkan pemimpin-pemimpin dari suku Jawa menjadi asisten bagi para pendeta Belanda. Tradisi Kristen di belakang sekolah ini adalah denominasi Calvinis Gereformeerd. Di tahun 1962 sekolah ini dan sekolah teologi serupa yang memiliki latar belakang denominasi Calvinis Hervormd menyatukan diri membentuk Sekolah Tinggi Theologia (STTh.) Duta Wacana. Jauh sebelum Sinode Nederlandse Hervormde Kerk (NHK) dan Sinode Gereformeerde Kerk in Nederland (GKN) di Belanda menyatukan diri menjadi Protestantse Kerk in Nederland (PKN) di tahun 2004, kedua sekolah teologi denominasi Calvinis yang berbeda di Indonesia sudah menyatukan diri mereka. Penyatuan kedua sekolah teologi Calvinis ini menciptakan praktik sosial yang mendorong segenap anggota komunitas belajar menghargai orang-orang yang berbeda dari mereka, meskipun samasama berasal dari denominasi Calvinis. Mereka menyadari bahwa jika mereka ingin mendapatkan kesejahteraan dan kelanggengan hidup bersama maka mereka harus belajar memerjuangkannya secara pro aktif. Mereka tidak lagi bisa mengatakan bahwa "kami benar" dan "kalian salah," atau bahwa "kami alkitabiah", dan "kalian tidak alkitabiah." Di sinilah seluruh anggota komunitas belajar memraktikkan empati, vulnerabilitas, kerendahan-hati, kesabaran, dan berbagai kebajikan lainnya yang dibutuhkan untuk hidup bersama yang lain yang berbeda dari dirinya.

Penyatuan ini tidak hanya menjembatani kesenjangan di antara dua kelompok denominasi yang serupa tapi tak sama itu, penyatuan ini juga pada gilirannya memungkinkan dua kelompok etnis yang berbeda, yaitu orang-orang indigenous Jawa dan orang-orang keturunan Tionghoa, untuk hidup bersama. Dalam perkembangannya, ketika para nara didik diwajibkan tinggal bersama di asrama, terjadi pula interaksi intens antara orang-orang yang kaya dan orang-orang

\footnotetext{
${ }^{36}$ Hillary Rodham Clinton, It Takes a Village (New York, N.Y: Simon and Schuster, 2012).

${ }^{37}$ Aristotle, Ethics, 1179b25-26 sebagaimana ditemukan dalam Stanley Hauerwas, A Community of Character: Toward a Constructive Christian Social Ethic (Notre Dame, Ind.: University of Notre Dame Press, 1981), 68.

${ }^{38}$ Alasdair C. Maclntyre, Whose Justice? Which Rationality? (Notre Dame, Ind.: Notre Dame University Press, 1988), 110.

${ }^{39}$ Sindhunata, "Politik Kebangsaan Dan Keadilan Sosial," Kompas. Com (Jakarta, June 3, 2000).
} 
yang miskin. ${ }^{40}$ Dengan demikian, penyatuan kedua sekolah teologi ini sebenarnya menjadi sebuah praktik sosial yang bagus untuk membentuk nasionalisme yang inklusif di mana berbagai sekat denominasi, etnisitas, dan status sosial-ekonomi dijembatani.

Beberapa tahun kemudian, sinode-sinode dari denominasi lain juga bergabung hingga membentuk lima sinode sebagai pemilik sekolah teologi ini. Salah satu sinode yang bergabung adalah Sinode GITJ (Gereja Injili di Tanah Jawa) yang mempunyai latar belakang tradisi Mennonite. Hal ini disusul kemudian oleh sinode berlatar belakang tradisi Mennonite lainnya, Sinode GKMI (Gereja Kristen Muria Indonesia). Bergabungnya beberapa sinode sebagai pemilik, menjadikan Duta Wacana sebagai sekolah teologi yang dimiliki oleh dua belas sinode berbeda. Hal ini membuat Duta Wacana menjadi sebuah eksperimen sosial gerejawi yang sangat unik, bukan saja di Indonesia tetapi juga di dunia, karena menjadi sekolah teologi yang mendidik para calon pemimpin gereja dan masyarakat, namun dimiliki bukan hanya oleh satu sinode atau beberapa sinode sealiran saja, melainkan dua belas sinode dari berbagai aliran denominasi yang sangat berbeda. Perkembangan ini mentransformasi praktik sosial yang sudah berjalan. Sekarang para dosen dan nara didik berlatar-belakang tradisi Calvinis harus hidup bersama dengan dosendosen dan para nara didik dari latar belakang tradisi Mennonite, sesuatu yang belum pernah terjadi sebelumnya secara formal institusional di belahan bumi manapun juga. Semua anggota komunitas dari beragam denominasi juga harus mengikut-sertakan dan berdialog dengan berbagai klaim kebenaran yang dimiliki oleh masing-masing kelompok. Dosen atau nara didik tidak lagi bisa mengatakan bahwa baptisan anak atau baptisan orang percaya sebagai baptisan yang benar, tidak pula mereka bisa mengatakan bahwa kelompok denominasi yang lain salah, tidak alkitabiah atau bahkan sesat. ${ }^{41}$ Demikian pula diskusi tentang kekerasan juga menjadi begitu kaya nuansa karena tradisi Just War kini bertemu langsung dengan tradisi Pacifism. Bahkan menarik juga dicermati bahwa sebagai seorang Mennonite yang bukan merupakan bagian dari kelompok dominan, saya pernah dipercayai menjadi Dekan Fakultas Teologi, Universitas Kristen Duta Wacana (UKDW), periode 2015-2019. Sebuah fenomena yang menunjukkan kepercayaan besar dari kelompok dominan kepada anggota komunitas yang jauh lebih kecil.

Semua anggota komunitas Duta Wacana kini harus belajar hidup dengan paradigma bahwa sementara aku/ kami benar, maka orang-orang yang lainpun juga bisa sama benarnya. Orangorang belajar meninggalkan spirit kompensasi berlebihan yang telah menjadi batu sandungan untuk membentuk kesaling-pemahaman dan penerimaan yang mutualistis di antara kelompokkelompok yang berbeda agar semua bisa berkembang. Rasa percaya diri yang berlebihan akan kepercayaan yang diyakini, sambil menyingkirkan orang-orang lain yang berbeda dan memandang mereka sebagai ancaman, dan bukan sebagai teman, kini ditinggalkan dan ditanggalkan. Orang-orang tidak perlu membuktikan kepada siapapun bahwa dirinya dan kelompoknya adalah yang benar dan superior. ${ }^{42}$ Sebaliknya mereka belajar memahami bahwa kebenaran yang mereka pegang teguh hanyalah sebagian kebenaran saja, tidak pernah merupakan seluruh kebenaran, dan bahwa persoalan utamanya tidaklah terletak pada ontologi kebenaran itu sendiri, melainkan pada epistemologi kebenaran.

Perjuangan ini menapaki jalur-jalur baru ketika terjadi rekrutmen dosen-dosen yang beragama Katholik. Diskusi-diskusi yang berkembang kini tidak lagi terbatas pada masalah baptisan atau masalah penggunaan kekerasan saja, tapi juga mencakup persoalan esensi dan identitas Gereja itu sendiri beserta semua sakramen dan ritual yang ada di dalamnya. Ekklesiologi tidak lagi satu sisi atau bahkan dua sisi, melain menjadi banyak sisi. Pertambahan jumlah nara didik dari latar belakang gereja-gereja Pentakosta dan gereja-gereja Injili Kharismatik menambah kekayaan keberagaman ini. Ketika di tahun 1985 STTh. Duta Wacana memutuskan untuk mengembangkan diri dari semula sekolah teologi saja menjadi sebuah universitas dengan berbagai program studi non-teologi, maka momentum ini makin memperluas keberagaman diskursus dan praktik sosial

\footnotetext{
${ }^{40}$ Emmanuel Gerrit Singgih, Menguak isolasi, menjalin relasi: teologi Kristen dan tantangan dunia postmodern (Jakarta: BPK Gunung Mulia, 2009), 67-68.

${ }^{41}$ Ibid., 68-69.

42 lbid., 72-73, 75-82.
} 
yang ada di kampus. Jembatan yang harus dibangun bukan saja jembatan yang bisa menjembatani keragaman denominasi, etnis, maupun status sosial-ekonomi, kini komunitas teologi juga harus berrelasi secara intens dengan komunitas-komunitas non-teologi.

Di tahun 2007 peziarahan praktik sosial dalam keberagaman ini bahkan berlanjut lebih jauh lagi melalui dua hal sekaligus. Yang pertama, pada tahun itu UKDW menjalin kerjasama formal dengan Universitas Gajah Mada dan Universitas Islam Negeri (UIN) Sunan Kalijaga untuk bersama-sama membentuk ICRS (Indonesian Consortium for Religious Studies) yang menawarkan program studi doktoral dalam Religious Studies. Mungkin fenomena ini merupakan satu-satunya fenomena di dunia, di mana sebuah lembaga pendidikan Kristen secara formal bekerjasama dalam sebuah konsorsium bersama lembaga pendidikan negeri dan lembaga pendidikan Islam. Yang kedua, pada tahun itu pula UKDW membuka program studi Kajian Konflik dan Perdamaian yang menerima mahasiswa-mahasiswa non-Kristen juga. Upacara wisuda menjadi sesuatu yang menarik perhatian karena sekarang ada mahasiswa-mahasiwa bernama Nurcholis, Siti Rofi'ah, Noor Anna, Ichram, Agustam Rachman, dan lain-lain yang diwisuda di Fakultas Teologi sebuah universitas Kristen. Pengalaman ini masih diperkaya dengan kegiatan-kegiatan pertukaran dosen dan mahasiswa di antara Duta Wacana dan UIN Sunan Kalijaga. Proyek-proyek penelitian bersama juga dilakukan, termasuk proyek publikasi bersama buku Meniti Kalam Kerukunan, yang mencoba menjelaskan berbagai istilah agama yang biasanya digunakan di kedua agama Kristen dan Islam supaya istilah-istilah ini bisa dipahami dengan baik oleh masyarakat biasa. ${ }^{43}$

Praktik sosial yang telah dijalani selama puluhan tahun menampakkan buah-buahnya. Segenap anggota komunitas Duta Wacana belajar untuk berempati dengan orang-orang lain yang memiliki latar belakang agama yang berbeda. Mereka juga belajar untuk menjadi rentan dan rendah hati, sambil memupuk pengharapan akan kebaikan yang akan lahir dari hubungan-hubungan ini. Semua ini bisa terjadi karena segenap anggota komunitas sudah terbiasa dengan lingkungan semacam itu. Orang-orang belajar untuk memiliki apa yang disebut sebagai "double vision," 44 bahkan "multivision." Beberapa mata kuliah yang mengajarkan tentang Islamologi dan juga tentang agama-agama lain serta berbagai aliran kepercayaan diajarkan; bukan dengan tujuan untuk mencari kelemahan dari agama-agama lain dan aliran-aliran kepercayaan yang hidup di masyarakat, melainkan untuk memahami agama-agama lain dan aliran-aliran kepercayaan tersebut dengan lebih baik agar bisa berinteraksi dengan orang-orang yang berbeda keyakinannya. Jika seandainya tidak ada sejarah praktik sosial yang begitu panjang di mana orang-orang belajar melintasi batas-batas denominasi, etnisitas, sosial-ekonomi, rumpun ilmu, dan agama maka komunitas Duta Wacana tidak akan pernah mampu berinteraksi begitu mendalam dengan orang-orang yang berbeda.

Ini tidak berarti, bahwa praktik sosial untuk memupuk nasionalisme yang inklusif di komunitas Duta Wacana berjalan tanpa hambatan. Sebagaimana yang terjadi di masyarakat luas, paradigma kelompok dominan juga seringkali masih menjadi paradigma yang taken for granted dan digunakan sebagai perspektif untuk menetapkan kebijakan dan mengambil keputusan di kampus. Ketika mendiskusikan relasi antara Fakultas Teologi UKDW dan gereja-gereja pendukung, misalnya, termasuk peran para dosen di gereja asal dan proses penerimaan calon mahasiswa baru, seringkali diasumsikan begitu saja bahwa gereja-gereja pendukung Duta Wacana beroperasi dengan sistem pemerintahan presbyterial. Padahal dalam kenyataannya ada gerejagereja pendukung yang beroperasi dengan sistem pemerintahan kongregasional yang sangat berbeda dari sistem presbyterial. Demikian pula epistemologi orang-orang Protestan yang cenderung menekankan rasio seringkali mengesampingkan epistemologi orang-orang dari denominasi lain yang lebih menekankan pengalaman rohani ataupun pemaknaan Alkitab secara normatif. Bahkan sekedar untuk membuat konsensus terkait karya macam apa yang bisa disebut akademisilmiah dan mana yang tidak akademis-ilmiah juga merupakan tantangan tersendiri. Namun,

\footnotetext{
${ }^{43}$ Mohamad Nur Kholis Setiawan and Djaka Soetapa, Meniti Kalam Kerukunan: beberapa istilah kunci dalam Islam dan Kristen, vol. 1 dan 2 (Jakarta: BPK Gunung Mulia, 2010).

${ }^{44}$ Alan Kreider, Eleanor Kreider, and Paulus Widjaja, A Culture of Peace: God's Vision for the Church (Intercourse, PA: Good Books, 2005), 82.
} 
terlepas dari semua tantangan tersebut, yang penting adalah kenyataan bahwa praktik sosial yang dengan sengaja dilakukan sebagai bagian integral dari proses belajar mengajar di Duta Wacana terbukti efektif membangun nasionalisme yang inklusif di antara para anggotanya. Kerjasamakerjasama lintas iman yang dilakukan secara institusional, disengaja, terstruktur, sistemik, berkesinambungan, dan bukan sekedar sebagai kegiatan-kegiatan insidental belaka, telah pula memperkuat praktik sosial ini.

\section{KESIMPULAN}

Dari apa yang sudah dipaparkan di atas, bisa diambil beberapa kesimpulan, sebagai berikut:

Pertama, nasionalisme Indonesia bersifat historis dan etis, bukan kesatuan alamiah. Itu sebabnya dibutuhkan upaya yang disengaja untuk memelihara, menjaga, dan menumbuh-kembangkan kesatuan tersebut.

Kedua, ancaman terbesar terhadap nasionalisme Indonesia datang dari Sentralisme, Primordialisme, dan Ketidak-adilan. Di sini perlu dicermati bahwa primordialisme yang dilandaskan pada politik identitas yang negatif seringkali bertransformasi menjadi nasionalisme berbasis agama dominan, di mana negara kemudian berpihak pada kelompok agama dominan dan melakukan represi pada kelompok-kelompok agama yang lebih lemah. Ketidak-adilan yang muncul dari pendistribusian keanggotaan yang tidak adil, beserta hak-hak asasi yang terkait dengannya, untuk melanggengkan rejim yang berkuasa, perlu pula dikritisi dan direformasi.

Ketiga, tujuan pendidikan, termasuk pendidikan teologi, bukanlah semata-mata untuk mengembangkan tingkat intelektualitas para nara didik, tetapi terutama untuk membentuk karakter mereka, bahkan juga semua pemangku kepentingan. Untuk itu, seluruh proses belajar mengajar harus menjadi praktik sosial yang membentuk karakter para nara didik menjadi nasionalisnasionalis yang inklusif. Ini terkait baik dengan kurikulum eksplisit, kurikulum implisit, ekstrakurikuler, maupun kurikulum null. Proses tersebut juga harus melibatkan semua pemangku kepentingan, baik mahasiswa, dosen, staf administrasi, pengurus Yayasan, serta gereja-gereja pendukung.

Segenap elemen bangsa Indonesia perlu belajar dari eco-system alam. Fakta tak terbantahkan dari alam adalah bahwa soliditas dan kelanggengan sebuah eco-system justru sangat bergantung pada keragamannya. Semakin keberagaman hayati bisa dijamin, maka semakin solid dan langgenglah eco-system-nya. Sebaliknya, semakin seragam dan mono kultur, maka semakin rapuh pulalah sebuah eco-system. Demikian pula halnya dengan bangsa Indonesia. Bangsa yang besar dan yang dari sejak awal mulanya sudah majemuk ini justru akan bisa bertahan solid dan langgeng, jika segenap elemen bangsa dengan sengaja memertahankan kemajemukan ecosystem ini. Jika itu impiannya, maka semboyan yang tepat untuk menumbuh-kembangkan nasionalisme yang inklusif seharusnya bukan sekedar unity in diversity, tapi haruslah bisa menjadi diversity for unity. Keberagaman dengan sengaja dipertahankan demi kesatuan, karena tanpa keberagaman maka bangsa Indonesia akan menjadi rapuh dan ambruk.

\section{REFERENSI}

Bagir, Zainal Abidin. "The Politics and Law of Religious Governance." In Routledge Handbook of Contemporary Indonesia, edited by Robert W. Hefner, 284-295. Abingdon: Routledge, 2018. Accessed July 2, 2020. https://www.routledge.com/Routledge-Handbook-ofContemporary-Indonesia/Hefner/p/book/9781138644427.

Clinton, Hillary Rodham. It Takes a Village. New York, N.Y: Simon and Schuster, 2012. Epafras, Leonard Chrysostomos, Hendrikus Paulus Kaunang, and Syamsul Asri. "Religious Blasphemy and Monitory Society in Indonesian Digital Age." Jurnal Kawistara 9, no. 2 (October 19, 2019): 220.

Hauerwas, Stanley. A Community of Character: Toward a Constructive Christian Social Ethic. Notre Dame, Ind.: University of Notre Dame Press, 1981.

lannaccone, Laurence R, and Eli Berman. "Religious Extremism: The Good, The Bad, and The Deadly." Public Choice 128 (July 28, 2006): 109-129. 
Ichwan, Moch Nur. "Manusiawi, Adil, Dan Beradab: Menuju Tadbir Humanistik Atas Keragaman Agama." In Islam, Agama-Agama, Dan Nilai Kemanusiaan: Festschrift Untuk M. Amin Abdullah, edited by Moch Nur Ichwan and Ahmad Muttaqin, 221-246. Yogyakarta: CISForm UIN Sunan Kalijaga, 2013.

IRIN. "How to Reverse Buddhism's Radical Turn in Southeast Asia?" Refworld. Last modified July 16, 2013. Accessed December 30, 2020. https://www.refworld.org/docid/51e9102b4.html.

Jonkers, Peter. "How to Break the III-Fated Bond between Religious Truth and Violence." In Religious Truth and Identity in an Age of Plurality, edited by Peter Jonkers and Oliver J. Wiertz, 246-263. London and New York: Routledge, 2019.

King, Martin Luther, Jr. "The Purpose of Education." The Maroon Tiger, February 1947. Accessed May 12, 2021. https://kinginstitute.stanford.edu/king-papers/documents/purposeeducation.

Kleden, Ignas. "Stratifikasi Etnis Dan Diskriminasi." In Pri Dan Nonpri Mencari Format Baru Pembauran, edited by Moch. Sa'dun M. Jakarta: Pustaka Cidesindo, 1999.

Kreider, Alan, Eleanor Kreider, and Paulus Widjaja. A Culture of Peace: God's Vision for the Church. Intercourse, PA: Good Books, 2005.

Kusumawardani, Anggraeni, and Faturochman. "Nasionalisme." Buletin Psikologi XII, no. 2 (Desember 2004): 61-72.

Maclntyre, Alasdair C. Whose Justice? Which Rationality? Notre Dame, Ind.: Notre Dame University Press, 1988.

Magnis-Suseno, Frans. "Persatuan Indonesia: Pancasila, Paham Kebangsaan Dan Integritas Nasional." In Pancasila Sebagai Ideologi Terbuka: Problema Dan Tantangannya, edited by Alex Lanur. Yogyakarta: Kanisius, 1995.

Milner IV, H. Richard. "Reimagining the Null Curriculum." Educational Leadership, November 2017. Accessed May 19, 2021. http://www.ascd.org/publications/educationalleadership/nov17/vol75/num03/Reimagining-the-Null-Curriculum.aspx.

Muttaqin, Ahmad. "Meneguhkan Harmoni Muslim-Kristen: Mengayuh Di Antara Problem Dan Potensi." In Islam, Agama-Agama, Dan Nilai Kemanusiaan: Festschrift Untuk M. Amin Abdullah, edited by Moch Nur Ichwan and Ahmad Muttaqin, 133-148. Yogyakarta: CISForm UIN Sunan Kalijaga, 2013.

Prasetyono, Eko, Riefki Muna, and Mahmud Syaltout. Kaji Ulang Indeks Keamanan Manusia Indonesia 2013. Jakarta: Kementrian PPN/Bappenas and United Nations Development Programme, 2013. Accessed September 16, 2021. http://ditpolkom.bappenas.go.id/basedir/Kajian\%20Ditpolkom/3)\%20Kajian\%20Tahun\%2 02014/Indeks\%20Keamanan/Indeks\%20Keamanan.pdf.

Riyanto, F. X. Eko Armada; Metodologi: Pemantik dan Anatomi Riset Filosofis Teologis. Malang: Widya Sasana Publication, 2020. Accessed September 18, 2021.

//librarystftws.org/perpus/index.php?p=show_detail\&id=17302.

Saiya, Nilay. "Pluralism and Peace in South Asia." The Review of Faith \& International Affairs 17, no. 4 (2019): 12-22.

Setiawan, Mohamad Nur Kholis, and Djaka Soetapa. Meniti Kalam Kerukunan: beberapa istilah kunci dalam Islam dan Kristen. Vol. 1 dan 2. Jakarta: BPK Gunung Mulia, 2010.

Sindhunata. "Politik Kebangsaan Dan Keadilan Sosial." Kompas.Com. Jakarta, June 3, 2000. Singgih, Emmanuel Gerrit. Iman dan politik dalam era reformasi di Indonesia. Jakarta: BPK Gunung Mulia, 2000.

_. Mengantisipasi Masa Depan: Berteologi Dalam Konteks Di Awal Milenium III. Jakarta: BPK Gunung Mulia, 2004.

_. Menguak isolasi, menjalin relasi: teologi Kristen dan tantangan dunia postmodern. Jakarta: BPK Gunung Mulia, 2009.

Stassen, Glen. "Michael Walzer's Situated Justice." The Journal of Religious Ethics 22, no. 2 (1994): 375-399. 
Upreti, B. C. "Nationalism in South Asia: Trends and Interpretations." The Indian Journal of Political Science 67, no. 3 (2006): 535-544.

van der Ven, Johannes A. Formation of the Moral Self. 1st edition. Grand Rapids, Mich: Eerdmans Pub Co, 1998.

Walzer, Michael. Spheres Of Justice: A Defense Of Pluralism And Equality. New York: Basic Books, 1984.

Widjaja, Paulus S. "Ketupat Nasi: Melampaui Perbuatan, Membentuk Karakter." In Tetap Setia Dan Menjadi Berkat, edited by Paulus S. Widjaja, 119-133. Yogyakarta: Komojoyo Press, 2021.

Widjaja, Paulus S., Djoko Prasetyo Adi Wibowo, Edy Nugroho, and Imanuel Geovasky. Dampak Politik Identitas Terhadap Perilaku Umat Kristiani Di Ruang Publik Di Daerah Istimewa Yogyakarta. Yogyakarta: Taman Pustaka Kristen, 2020. Accessed May 17, 2020. http://library.ukdw.ac.id/main/opac/index.php?p=show_detail\&id=46326.

Widjaja, Paulus Sugeng, Djoko Prasetyo Adi Wibowo, and Imanuel Geovasky. "Politik Identitas Dan Religiusitas Perdamaian Berbasis Pancasila Di Ruang Publik." GEMA TEOLOGIKA: Jurnal Teologi Kontekstual dan Filsafat Keilahian 6, no. 1 (April 30, 2021): 95-126.

"2021 Storming of the United States Capitol." Wikipedia, May 23, 2021. Accessed May 23, 2021.

https://en.wikipedia.org/w/index.php?title=2021_storming_of_the_United_States_Capitol\& oldid=1024667406.

"Messi vs Ronaldo - All Time Career Goals and Stats." MessivsRonaldo.App. Accessed May 19, 2021. https://www.messivsronaldo.app/. 